\title{
On the Biology of Pediobius imbreus (Hymenoptera: Eulophidae), A Hyperparasite of Opisina arenosella. the Black-Headed Caterpillar of Coconut
}

\author{
S. M. GHOSH and U. C. ABDURAHIMAN \\ Division of Entomology, Department of Zoology, University of Calicut, \\ Kerala-673 635, India
}

\section{ABSTRACT}

Pediobius imbreus (Walker), a hyperparasite of Opisina arenosella, is distributed throughout Kerala. The biology of this hyperparasite was studied in the laboratory. The mating process took, on an average, $43 \mathrm{sec}$. The female started to lay eggs on the same day of emergence and laid upto 30 eggs in her life time.

The eggs hatch after 36 to $40 \mathrm{~h}$. of incubation. There were three larval stages. The duration of the immature stages from egg to adult emergence was completed in 412 to $420 \mathrm{~h}$, and was dependent on temperature.

\section{INTRODUCTION}

Opisina arenosella Walker (Lepidoptera: Oecophoridae) is attacked by several parasitoids and predators. some of which in turn are attacked by certain hyperparasites. Pediobius imbreus is an important hyperparasite of Bracon brevicomis Wesmael, an important prepupal parasitoid of $O$. arenosella. $P$. imbreus is distributed throughout Kerala and is commonly found in Malabar area. Although it is a hyperparasite of $\boldsymbol{B}$. brevicornis, it has been observed to attack two other parasitoids of $O$. arenosella, namely Apanteles taragamae Wilkinson and Goniozus nephantidis Mues.

No study has so far been undertaken on this hyperparasite. In the present paper some aspects of the biology of $P$. imbreus is given.

\section{MATERIALS AND METHODS}

Pupae of Pediobius imbreus collected from the field along with Bracon brevicornis cocoons served as nucleus cultures for laboratory studies. The hyperparasite was maintained in the laboratory on B. brevicornis, while the latter was maintained on an alternate host reared in wheat flour. Various aspects of the biology were studied using these laboratory-bred hyper-parasites. The biology of immature stages was studied by dissecting the host to remove hyperparasite larvae which were studied under the microscope.

\section{Mating:}

\section{OBSERVATIONS AND DISCUSSION}

After locating the female, the male follows her while fluttering the wings. Once the male is close to the female, there is antennal contact. The receptive female remains motionless. The male extends the forelegs towards the abdomen of the receptive female, keeping the antennae forwardly directed and fluttering the wings. The male then mounts the female for copulation. The process of mating takes, on an average, $43 \mathrm{sec}$. 


\section{Oviposition:}

The female starts to oviposit on the day of emergence. As $P$. imbreus is highly specific on the exact developmental stage of the host, it lays eggs only on the prepupal stage of Bracon brevicornis. When the adult $P$. imbreus locates a cocoon mass of $B$. brevicornis of appropriate stage of development, it searches actively with the antennae for a suitable place to oviposit. On locating a suitable cocoon, it bends its abdomen so that the tip of the ovipositor touches the surface of the selected cocoon. When the female straightens the abdomen, the evipositor assumes a.perpendicular position relative to the cocoon in order to pierce it and deposit the egg. After laying one egg, it withdraws the ovipositor and repeats the process for further egg laying, until the entire cocoon mass is searched.

During oviposition, the antennae of the female remain folded and are kept close to the head, keeping in contact with the host cocoon. In some cases, the parasite makes two or three prickings on the host pupa and feed on the body fluid that oozes out. The whole process of oviposition was completed in $30 \mathrm{sec}$.

Pediobius imbreus exhibited arrhenotokous parthenogenesis. Mated females produced bisexual progeny with a high female; male ratio. A female could lay up to 30 eggs during the life time . After one week of emergence, the number of eggs laid per day decreased considerably.

\section{Effect of Oviposition on the host:}

Field studies indicated that in a few instances, nearly $50 \%$ of the parasitoid cocoons collected were parasitised by $P$. imbreus. The adult $P$. imbreus when in contact with host cocoons, pierces almost all of them. However, eggs are laid only in the prepupal stage and that too in about 8 to 10 prepupae of the cocoon mass. However, majority of the balance cocoons do not develop due to feeding by the hyperparasite. If the host was in the pupal stage, attempts of oviposition damages them causing them to deform and abort further development. However, accasionally, such pupae develop into abnormally small individuals. If the host was in the late larval stage, oviposition will cause excessive oozing of body fluids leading to death.

\section{Rate of hyperparasitism}

Pedioboius imbreus is distributed throughout Kerala. The population of the host, B. brevicornis, depends on the population of Opisina arenosella, and it usually high during the dry season and low during the wet season. Due to the harmful activity of the hyperparasite, the population of $B$. brevicornis does not develop to the expected level, causing outbreaks of $O$. arenosella.

Egg: The mature egg is translucent and white in colour and measured $0.325 \pm 0.008$ $\mathrm{mm}$ in length and $0.08 \pm 0.01 \mathrm{~mm}$ in width. The size slightly increased after it was laid in the body cavity of the host, where it measured $0.35 \pm 0.01 \mathrm{~mm}$ in length and $0.09 \pm$ $0.01 \mathrm{~mm}$ in width.

As incubation proceeds, the developing larva could be seen through the transparent chorion of the egg. During February/March period, eggs hatch out in $36-40 \mathrm{~h}$. 

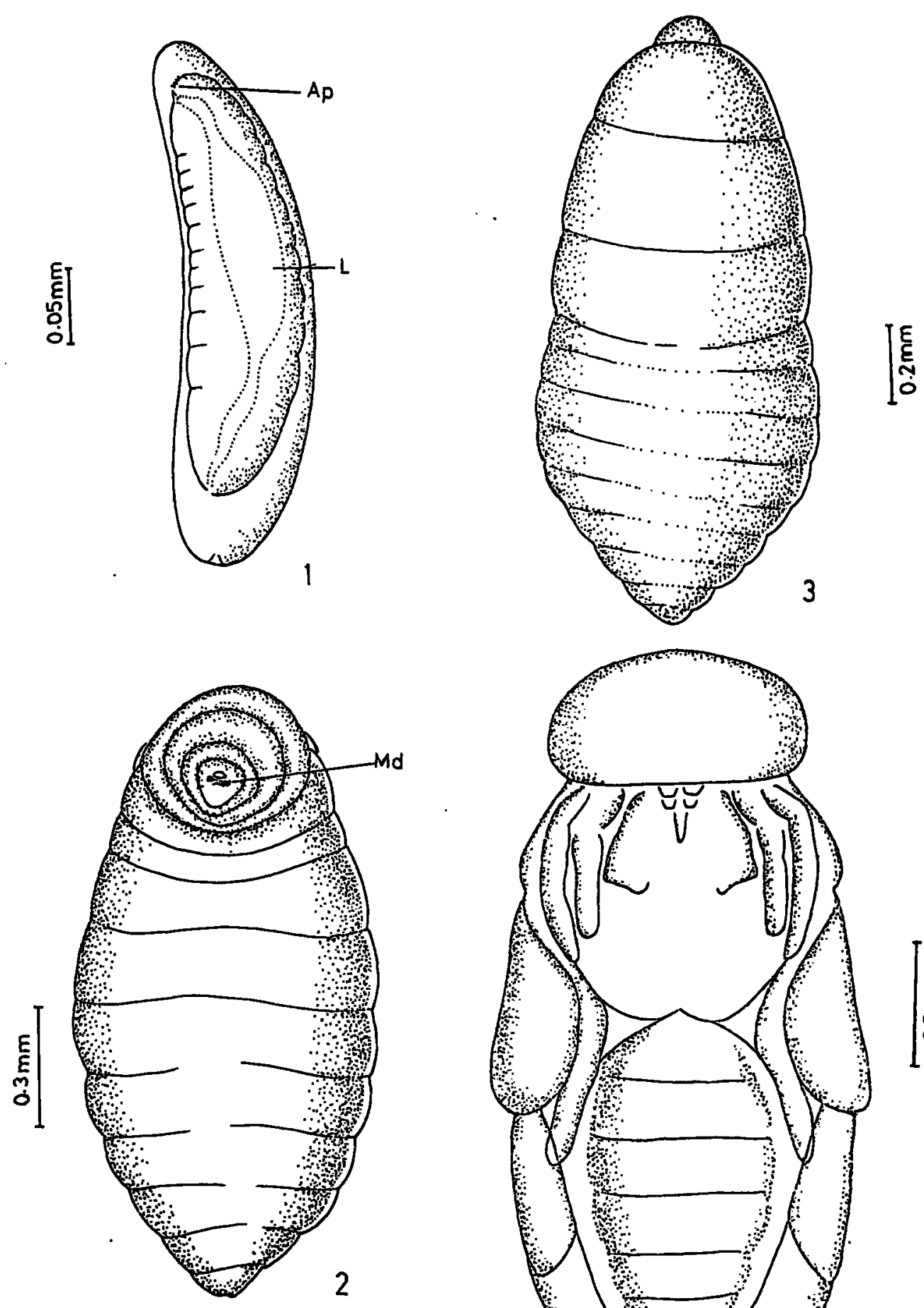

Fig.1: Immature stages of Pediobius imbreus

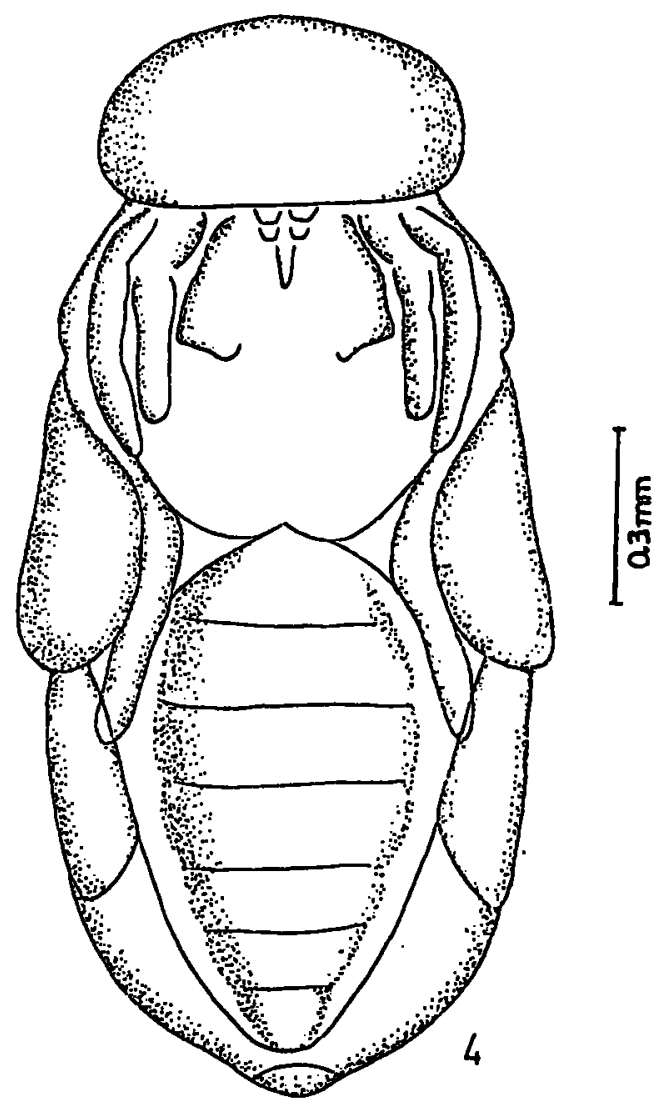

Fig. 1: Immature stages of Pediobius imbreus 


\section{S. M. GHOSH and U. C. ABDURAHIMAN}

Larval Stages: Pediobius imbreus has three larval instars. The first instar larva is $0.3 \mathrm{~mm}$ in length and $0.08 \mathrm{~mm}$ in width. The last abdominal segment has a semicircular caudal plate which carries a few spines. The second and third instars are almost similar but do not have a caudal plate. The third instar is $1.75 \pm 0.18 \mathrm{~mm}$ in length and $0.8 \pm 0.2$ $\mathrm{mm}$ in width and has a bilobed caudal segment. Well developed tracheal system with nine spiracles was present in the third instar. The larval stages require about $140 \mathrm{~h}$. for completion. The prepupal period lasted $20 \mathrm{~h}$.

Pupa: The pupa is exarate.It measured $1.6 \pm 0.2 \mathrm{~mm}$ in length and $1 \pm 0.2 \mathrm{~mm}$ in width. The male pupa is smaller than the female pupa. The pupal period lasted 8 to 10 days. The imaginal moult occured at 348 to $355 \mathrm{~h}$. after oviposition. The duration of the immature stages from egg to imaginal moult extended from 412 to $420 \mathrm{~h}$. depending on the ambient temperature.

\section{DISCUSSION}

Although detailed biological notes on several parasitoids of Opisina have been given by different authors, only very little information is available on the hyperparasites. The studies indicated that Pediobius imbreus could considerably reduce the efficiency of an important parasite Barcon brevicornis.

The life-cycle and development of $\boldsymbol{P}$. imbreus resemble those of $\boldsymbol{P}$. foveolatus, which is a gregarious primary parasitoid of phytopghagous epilachnine beetle (Bledsoe $e t$ al. 1983). Although $P$. imbreus has only three larval instars, Lall (1961) reported four larval instars in $P$. foveolatus, even though others have contradicted this observation (see Clausen, 1940).

It was also obvious that temperature has a profound effeot on the development of the hyperparasite. During dry months $P$. imbreus required 348 to 355 h. for full development while in wet months the period was $412 \mathrm{~h}$. to $420 \mathrm{~h}$. Similar observations have been made in respect of $P$. foveolatus (Lall, 1961).

\section{ACKNOWLEDGEMENTS}

The authors are thankful to Prof. K. J. Joseph, Head of the Department of Zoology for the facilities provided. One of them (SMG) is thankful to the University and to the U.G.G. for a research fellowship.

\section{REFERENCES}

Bledsoe, L. W., Flanders R. V. and Edwards C. R. (1983) Morphology and development of the immature stage of Pediobius fovelatus (Hymenoptera: Eulophidae). Ann. Ent. Soc. Am. 76, 953-957.

Clausen, C. P. (1940) Entomophagous insects. New York and London.

Lall, B. S. (1961) On the biology of Pediobius fovelatus (Crawford)(Eulophidae: Hymenptera). Ind. J. Ent. 23, 268-273. 